\title{
STUDY THE HARMFUL EFFECTS OF DIETHYL PHTHALATE ON LIVER AND TESTES OF MALE MICE, (Mus musculus)
}

\author{
Irum Naureen (Assistant professor), Aisha Saleem (M. Phil researcher) Attique Nawaz (M.Phil \\ researcher), Irum Ghaffar (M.Phil researcher), Israr Maqbool ( PhD researcher)
}

\author{
School of Zoology Minhaj University Lahore Pakistan
}

\begin{abstract}
Purpose The current study was designed in order to evaluate the harmful effects of Diethyl Phthalate (DEP) on testes and liver of 8 weeks-old mouse Mus musculus, which were grouped as Control group and Experimental groups. Control group was given corn oil and experimental groups were given dose of DEP I $1.2 \mathrm{mg} / \mathrm{g} \mathrm{B.W}$ and DEP II $1.60 \mathrm{mg} / \mathrm{g} \mathrm{B}$.W in super refined corn oil with the help of syringe for 21 days. Dose quantity was $0.1 \mathrm{ml}$. Glutathione Peroxidase 5(GPx5) and Malondialdehyde (MDA) hormones were used. Morphological examination was done on both experimental group and control group. Methods In Dose group, DEP I $(1.2 \mathrm{mg} / \mathrm{g} \mathrm{B} \mathrm{W})$ various deformities were observed i.e. wrinkled surface, shrinkage and reduced size of testes, while in dose group, DEP II (1.60 mg/g BW) showed abnormalities in their size, appearance, shape, their surface become wrinkled and shrinkage of cell also observed. In Morphometric analysis the control and experimental group showed significant results regarding length, width and weight. In control group there is no certain change in the weight, length and width of testes of male mice, whereas in dose group, DEP $1(1.2 \mathrm{mg} / \mathrm{g}$ B.W $)$ and DEP II $(1.60 \mathrm{mg} / \mathrm{g}$ B.W $)$ shows the significant effects on decreasing length, width and weight of testes in both groups. In the current experiment, the glutathione level has decreased after the intake of dose in male mice. Experimental group show decreased level of glutathione while control group show the normal level. In the recent experiment the level of Malondialdehyde (MDA) significantly increased after administration of certain doses. In control group, MDA level remains normal while in the experimental group, MDA level increases and the antioxidant enzyme of testicles, glutathione peroxidase (GPx) and a hormone testosterone significantly decreased. Liver histological examination in control group show
\end{abstract}

normal deposition of glycogen, normal and intact association of sinusoid, portal vein, with complete lobular boundary, and appearance of hepatocytes has been observed. In dose group, DEP I $(1.2 \mathrm{mg} / \mathrm{g} \mathrm{B.W})$ showed defects like appearance of mitotic cells, degeneration of hepatocytes, broad sinusoidal spacing and degeneration of kuppfer cells observed, while in DEP II (1.60 mg/g B.W) showed abnormalities like interrupted sheet of hepatocytes, vacuolization, degenerative cells and absence of coniculus cells was observed. In histological analysis, control group of testes showed the sperm located in lumen of tubules, round shape somniferous tubules, germinal epithelium, interstitial cells and peritubular myoid cells in same location, while in experimental group, different deformities observed as vacuolization, interstitial cells rupturing, lumen occupied with destroyed sperm, degenerative sperms, germinal epithelium rupturing, and hyalinization. Conclusion It is additionally noticed that DEP exerts sharp variations in testosterone level content is causing these defects ultimately. Variations are also observed in stress mediators like Glutathione and MDA. It is concluded from the current study that environmental introduction to DEP can be correspondingly dangerous to not only mice but also for man.

Key words: Diethyl Phthalate, testes, liver, male mice (Mus musculus),

\section{INTRODUCTION}

Phthalates are phthalic acid's diesters (1,2-benzene dicarboxylic acid) used as natural artificial compounds utilized in businesses as plasticizers, solvents, and added substances in PVC (polyvinyl chloride) plastics or individual consideration items (PCPs). ${ }^{(11)}$ The use of DEP as an added substance in polyvinyl chloride (PVC) to confer the adaptability of plastic has prepared phthalates well known the world over. The diet contains a significant wellspring of 


\section{International Journal of Engineering Applied Sciences and Technology, 2021 \\ Vol. 6, Issue 5, ISSN No. 2455-2143, Pages 47-60 \\ Published Online September 2021 in IJEAST (http://www.ijeast.com)}

presentation to high atomic weight of phthalates, particularly DEP. (7) specifically, nourishments bundled in PVC materials add to introduction to DEP in people. Phthalates are viewed as endocrinedisturbing mixture. One of the most critical phthalate's effect is as far as fetal turn of events and conceptive peculiarities and is alluded to as "phthalate condition" (e.g., formative or testicular effects, insulin like factor 3 creation) Also, phthalate presentation may be connected to insulin opposition and stoutness in human populaces. The DEP is main phthalates found in human pee is makeup and individual consideration items. Studies have announced raised convergences of phthalates in indoor air and residue. Truth be told, among different contaminants estimated in indoor residue, phthalates, particularly DEP and DEHP, are the significant pollutants in air and indoor residue. ${ }^{(6)}$ In vivo DEHP presentation at a convergence of $500 \mathrm{mg} / \mathrm{kg} / \mathrm{day}$ in mice prompted a decrease spermatozoon, the aptitude of fertilization and undeveloped organisms and decrease in formative potentiality. ${ }^{(4)}$ Mice treated with DEHP for 1month brought about a 3-overlap expanded recurrence of genomic DNA mutations. DEHP additionally expanded mutagenic dangers, particularly in the testis of mice. Germ cells of testicles get disturbed after the administration of DEHP and hindered spermatogonial immature microorganisms of descendants of different ages. The phthalates frequently result from clinical treatments. Both DEHP and DEP are consolidated in clinical gear, and DBP and DEP can be originate in the enteric covering of oral prescriptions. ${ }^{(3)}$ In light of its utilization in clinical gear, levels of DEP can arrive at $8.5 \mathrm{mg} / \mathrm{kg} /$ day following transfusions of blood $\mathrm{mg} / \mathrm{kg} /$ day extracorporeal layer oxygenation and 0.36 $\mathrm{mg} / \mathrm{kg} /$ day hemodialysis, methodology in children. The toxicological investigations have affirmed that DEP can go about as an endocrine disruptor and conceptive poison. ${ }^{(17)}$ DEP unfavorably influences the advancement of male regenerative region, and lessens semen quality. ${ }^{(4)}$ The testicular harmfulness of
DEP at gonad toxic levels lessens the size, which is related with testicular decay, reduces level of sperm of epididymis thickness ${ }^{(2)}$ and motility, and expanded quantities of strange sperm in male rodents. Regardless, the part response to DEP isn't non monotonic during youthfulness. ${ }^{(2)}$ Low portions could animate immaturity; in any case, low bits of 10 or $100 \mathrm{mg} / \mathrm{kg} /$ day didn't cut down the age at pubescence or update level of testosterone, and high doses of DEP (300 and $900 \mathrm{mg} \mathrm{DEP} / \mathrm{kg} /$ day) didn't extend testosterone serum or revive pubescence. The DEP as an estrogen substance affected conceptive wellbeing, for example, testicular atrophy. ${ }^{(1)}$

\section{STUDY DESIGN AND METHODOLOGY}

This is an experimental study.

A set of 30 male mice (Swiss Webster variety of Mus musculus) attained for the research process from the veterinary Research Institute, Lahore. An animal group was maintained under control condition such as 12 hour dark/light cycle, temperature of $27 \pm 2^{\circ} \mathrm{C}$ and the humidity $40-50 \%$ in the house of animal. Animal were set aside in iron cages. Commercially synthesized feed was given to mice, (Chick feed No.14 the National feeds, Lahore). Feed is known to contain proteins, multivitamins and minerals. The regular supply with fresh water in glass bottles was also settled daily. Cleanliness was maintained on daily basis in the animal house.

\section{QUANTITY OF DOSES}

Single dose of DEP $(1.60 \mathrm{mg} / \mathrm{g} \mathrm{B.W})$ or $(1.2 \mathrm{mg} / \mathrm{g}$ B.W) in Super Refined Corn Oil was given to the 10 mice per group with the help of oral syringes for 21 days on daily basis. The dose of $0.1 \mathrm{ml}$ was forced into the throat with the help of syringe. Mice were consumed with oral dose at once. The dose was given in such a way that dose wouldn't loss its quantity. 

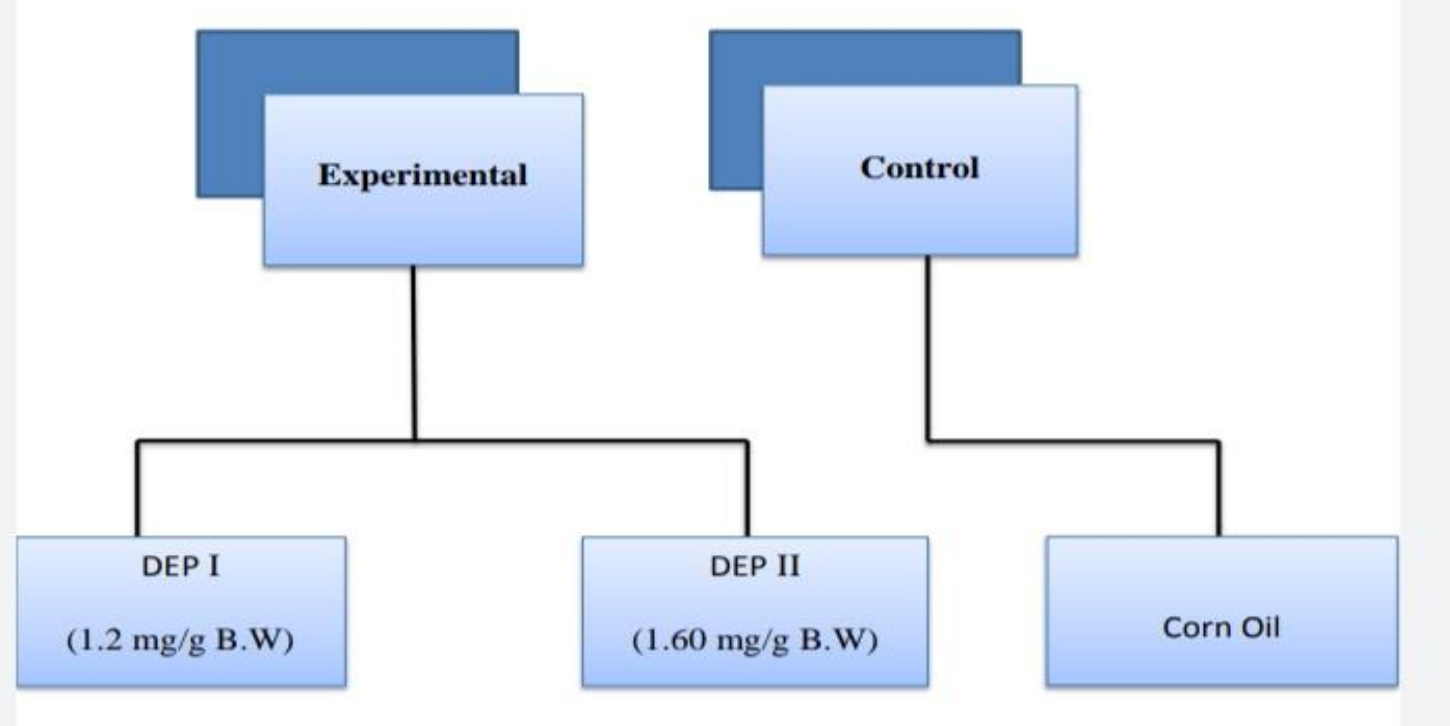

Figure 1: Scheme representing the administration of different doses of DEP

\section{HORMONE MEASUREMENT}

Blood sample were directly collected from eyes of male mice for evaluation of hormones, oxidants and anti-oxidants. 1) Testosterone: The Radio immune assay (RIA) technology was used to measure the level of testosterone.

\section{2) Glutathione Peroxidase 5(GPx5)}

The Glutathione Peroxidase is assessed by a technique Radio Immunoassay (RIA). This invention uses two high fondness monoclonal antibodies.

\section{Surgical incision of male mice}

Surgical incision was given and required organs were removed.

\section{Tissue Sampling and Processing}

$0.9 \%$ of saline pour into Petri dish and animal's testes were placed into it. For its preservation, testes were retained in Bouin's fixative.

\section{Morphological and Morphometric analysis}

Various deformities have been observed in testes after observing under binocular stereoscopic microscope. After that microphotographs were taken of deformed testes with the digital camera. In morphometric analysis, by the Vernier caliper measure the length and width of testes of dose and control groups. To measure the weight of tests of each group the digital weighing balance was used. Treated groups showed various abnormalities.

\section{HISTOLOGICAL ANALYSIS}

It was a processed study of testes in each group for the histological examination. During this analysis tissues were dehydrated in various grades of alcohols. After clearing the embedding tissues were transitionally cut at $6-7 \mu \mathrm{m}$ at microtome. The successive areas were stretched out on perfect slides which were covered with albumen. Eosin and Hematoxylin are used to stain the slides. Slides were prepared by the microscope and microphotographs taken from the desired sections with the help of Labomed (Irmeco) a magnifying instrument at 400X.

Statistical analysis: Computer based values were achieved by using SPSS one-way ANOVA, to complete the examination. A probability level of $\mathrm{p}$ $<0.001$ was measured significant.

\section{RESULTS}

Control Group: Control group were showed the normal appearance. Testes surface seemed to be smooth and shiny. They appeared heavy and large. Color of testes appeared creamy. (Fig 1.1, 1.2)

\section{Experimental Group}

\section{1-Dose Group DEP I (1.2 mg/g B.W):}


Morphological examination showed various deformities in experimental groups. In dose group DEP I (1.2 mg/g B.W) testes were irregular and their surface become wrinkled. Normal shape does not maintain by testes. (Fig 1.3, 1.4)

\section{2-Dose Group DEP II (1.60 mg/g B.W)}

Dose group DEP II (1.60 mg/g B.W) showed improvement in the size and shape of testes of all the groups. They showed wrinkles on their surfaces. Their surfaces appeared to be wrinkled. (Fig 1.5, 1.6)

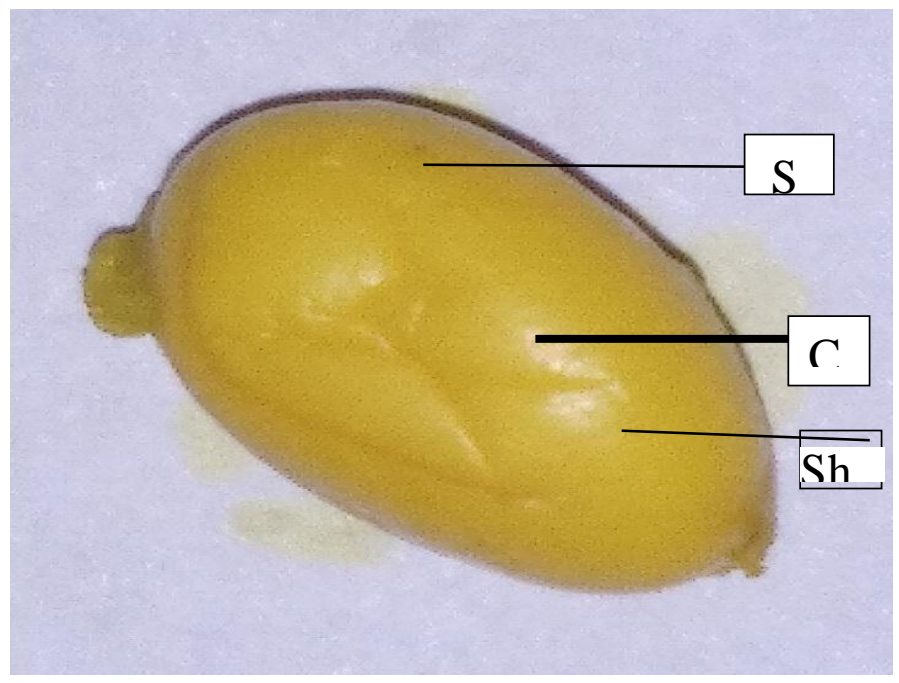

Fig 1.1: testes of 8-week-old mouse of control group $\mathbf{C r}$ : creamy color Sh: shiny surface Sm: smooth surface

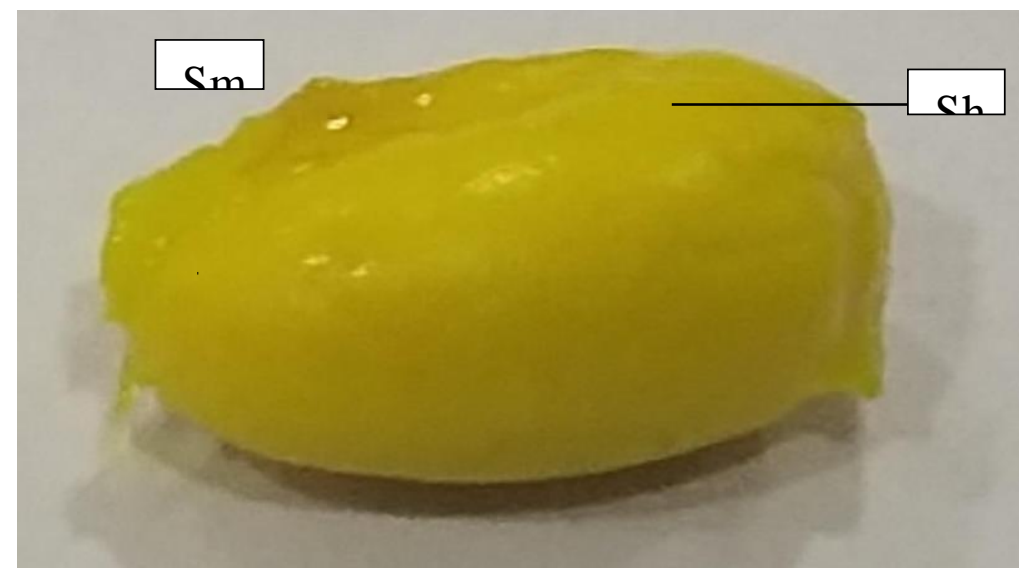

Figure 1.2: Macro photograph of testes of 8-week-old mouse of control group (C)

Sm: smooth surface s: shiny surface 


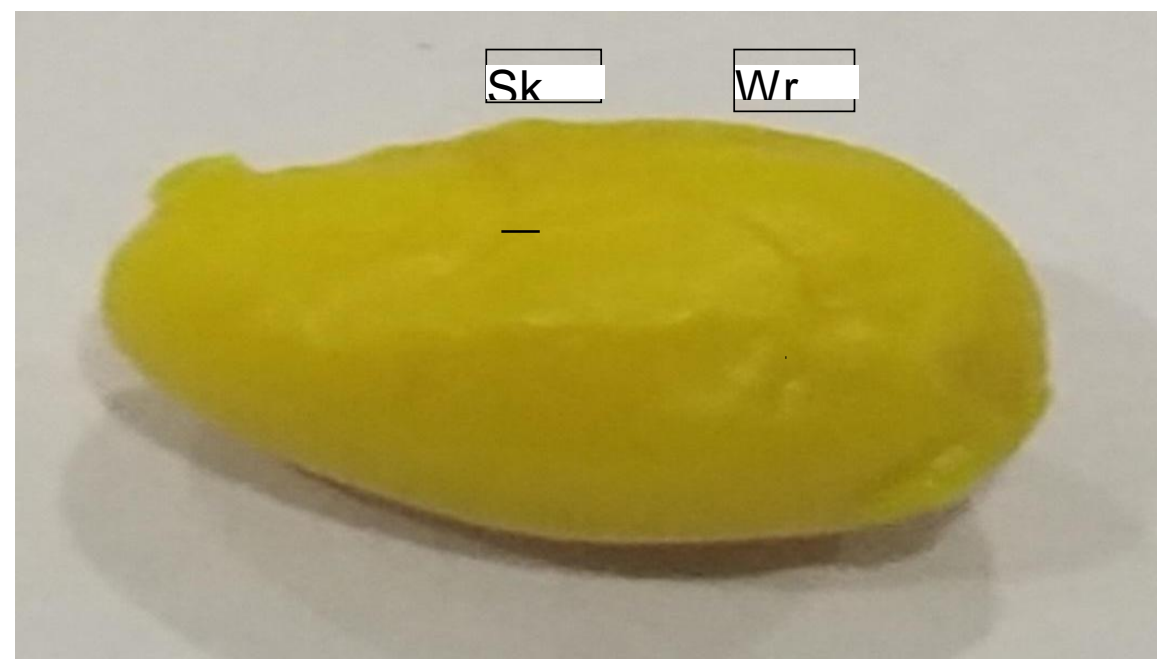

Figure 1.3: Macro photograph of testes of 8-week-old mouse of dose group DEP I (1.2 mg/g B.W) SK: shrinkage Wr: wrinkled surface.

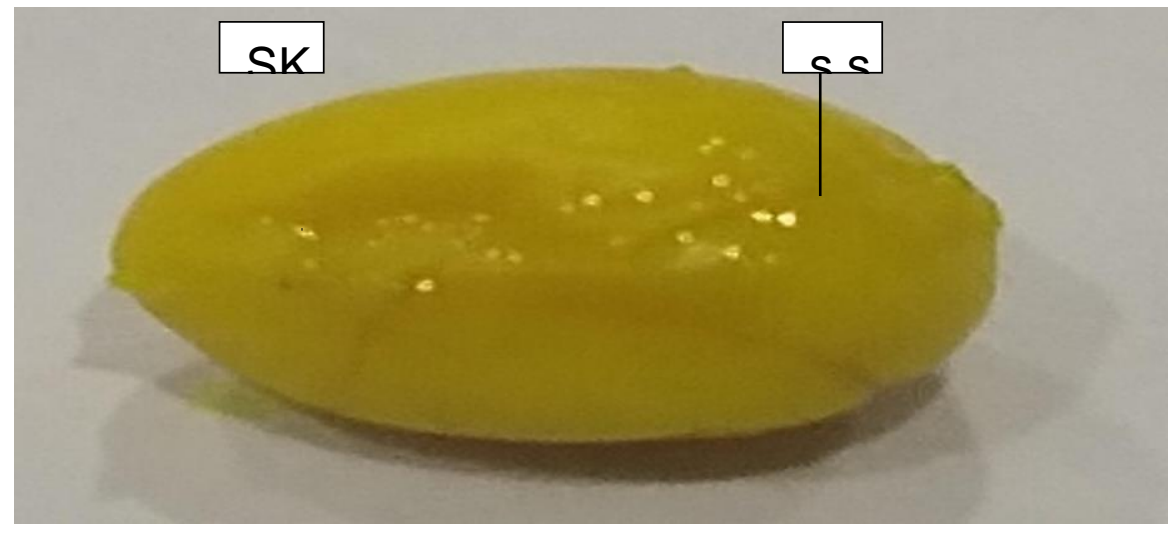

Figure 1.4: Macro photograph of testes of 8-week-old mouse of dose group DEP I (1.2 mg/g B.W) Sh: shrinkage, S.s: Small size.

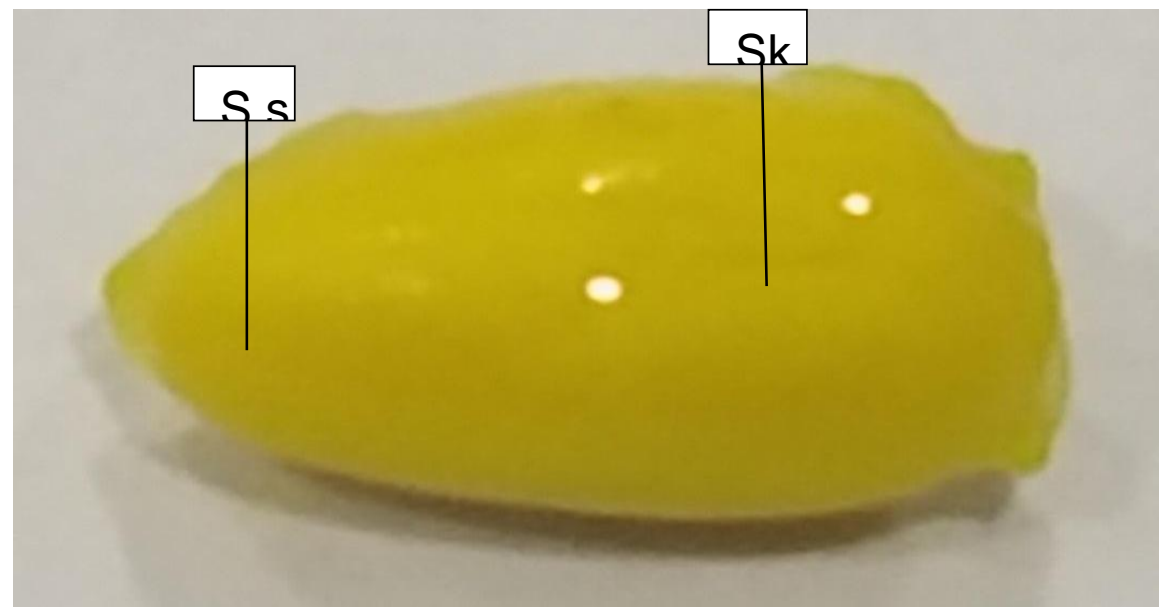

Figure 1.5: Macro photograph of testes of 8-week-old mouse of dose group DEP II (1.60 mg/g B.W) S.s: Small size SK: shrinkage surface. 


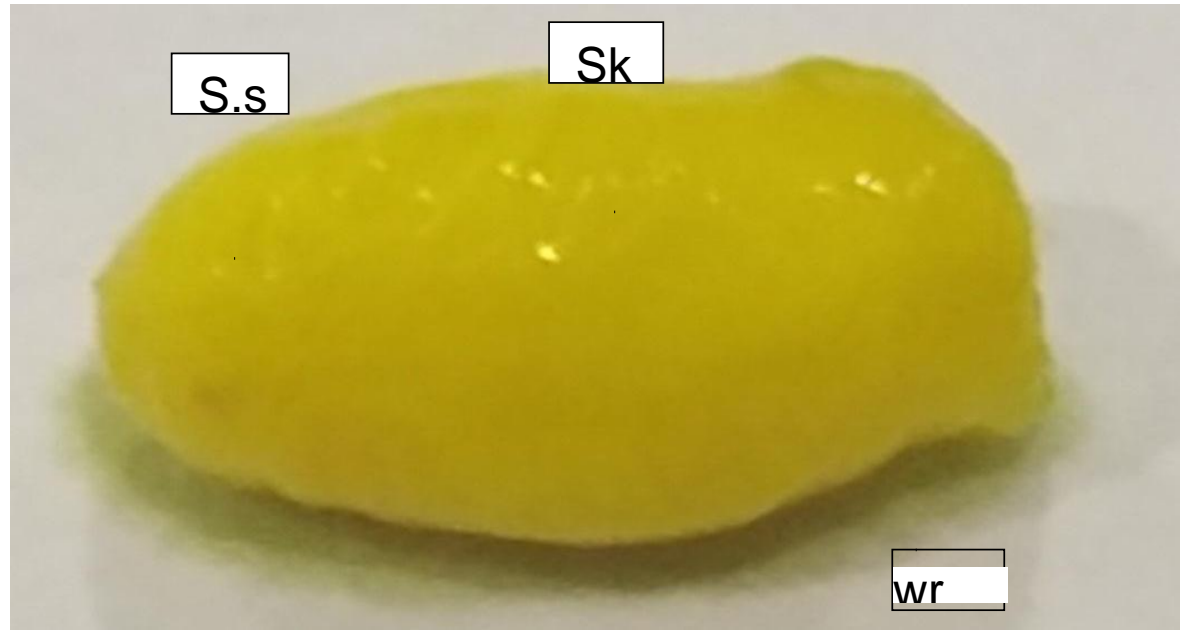

Figure 1.6: Macro photograph of testes 8 -week-old mouse of dose group DEP II ( $1.60 \mathrm{mg} / \mathrm{g} \mathrm{B.W}) \quad$ S.s: Small size, Wr: wrinkled surface, SK: shrinkage surface.

\section{MORPHOMETRIC ANALYSIS}

\section{Control group}

In morphometric analysis, normal features were shown by control. The average length of testis was $7.2 \mathrm{~mm} \pm 0.54$ and the average width of testes was 4.2 $\mathrm{mm} \pm 0.1$. Whereas the average weight of testes of control group was $91.4 \mathrm{mg} \pm 0.9$. (Table; 4.1 Fig no; $4.11,4.12,4.13)$

\section{Experimental Group}

\section{1-Dose group DEP I (1.2 mg/g B.W)}

Testes isolated from the dose group DEP I $(1.2 \mathrm{mg} / \mathrm{g}$ B.W) were also showing the morphometric analysis. Morphometric analysis showed the average length of the testes was $5.30 \mathrm{~mm} \pm 0.1$, which was significantly lower $(\mathrm{p}<0.001)$ than control group (table 1; Fig no;
1.7). Similarly the average width of the testes was $3.5 \mathrm{~mm} \pm 0.08$, that was also considerably less $(p<0.001)$ than the control group (table 1; Fig no; 1.8), while the average weight of testes was found to be $84.4 \mathrm{~mm} \pm 11.5$, which also showed the significant decrease $(\mathrm{p}<0.001)$ as compare to control. (Table 1; Fig no: 1.9$)$

\section{2-Dose Group DEP II (1.60 mg/g B.W)}

Testes from the dose group DEP II (1.60 mg/g B.W) represented following changes in morphometric analysis. The average length of testes was 4.1 $m m \pm 0.05$, which was significantly $(p<0.001)$ lesser than control group. The average width of the testes was $2.9 \mathrm{~mm} \pm 0.04$ and it was also significantly $(p<0.001)$ lower than the control. Similarly the standard weight of the testes was $64.0 \mathrm{~mm} \pm 16.7$, which was the significantly $(\mathrm{p}<0.001)$ reduced than control.

Table: 1 Effects of different doses of Diethyl Phthalate on length, width and weight of testes of 8- week-old mouse.

\begin{tabular}{|l|l|l|l|}
\hline Dose group & $\begin{array}{l}\text { Average length of } \\
\text { testes }(\mathbf{m m} \pm \text { S.D) }\end{array}$ & $\begin{array}{l}\text { Average width of } \\
\text { testes }(\mathbf{m m} \pm \text { S.D) }\end{array}$ & $\begin{array}{l}\text { Average weight of testes } \\
(\mathbf{m g} \pm \text { S.D })\end{array}$ \\
\hline Control & $7.2 \pm 0.54$ & $4.2 \pm 0.01$ & $91.4 \pm 0.9$ \\
\hline DEP I & $* * * 5.3 \pm 0.1$ & $* * * 3.5 \pm 0.08$ & $* * * 84.4 \pm 11.5$ \\
\hline
\end{tabular}


International Journal of Engineering Applied Sciences and Technology, 2021

Vol. 6, Issue 5, ISSN No. 2455-2143, Pages 47-60

Published Online September 2021 in IJEAST (http://www.ijeast.com)

\begin{tabular}{|l|l|l|l|}
\hline DEP II & $* * * 4.1 \pm 0.05$ & $2.9 \pm 0.04$ & \\
& & & \\
\hline
\end{tabular}

NOTE: Asterisks indicate significant difference against ${ }^{* * *}=\mathrm{p}<0.001$

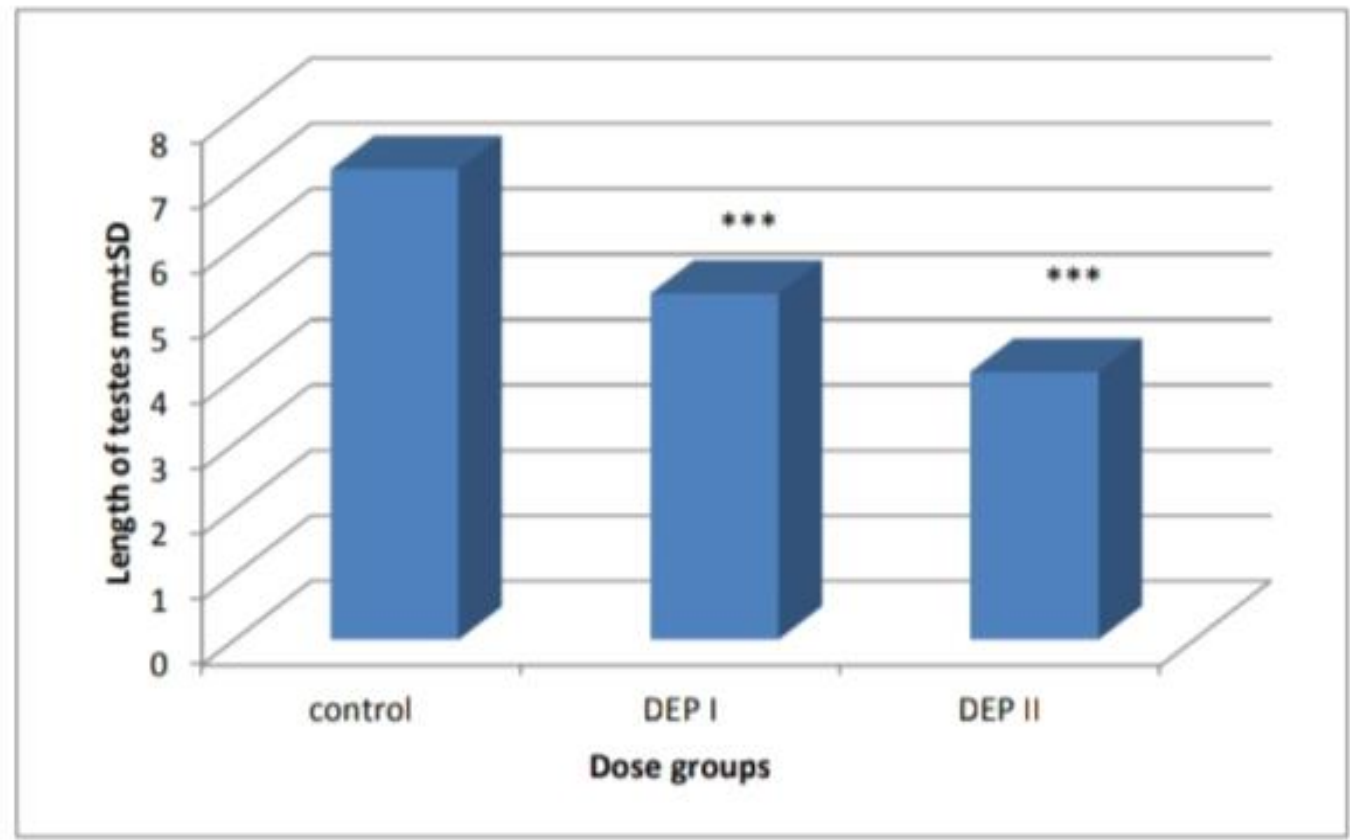

Figure 1.7: Histogram showing the effect of DEP on the length of testes of 8-week-old mouse.

Note: Asterisks indicate the significant difference against $* * *=p<0.001$ 
International Journal of Engineering Applied Sciences and Technology, 2021

Vol. 6, Issue 5, ISSN No. 2455-2143, Pages 47-60

Published Online September 2021 in IJEAST (http://www.ijeast.com)

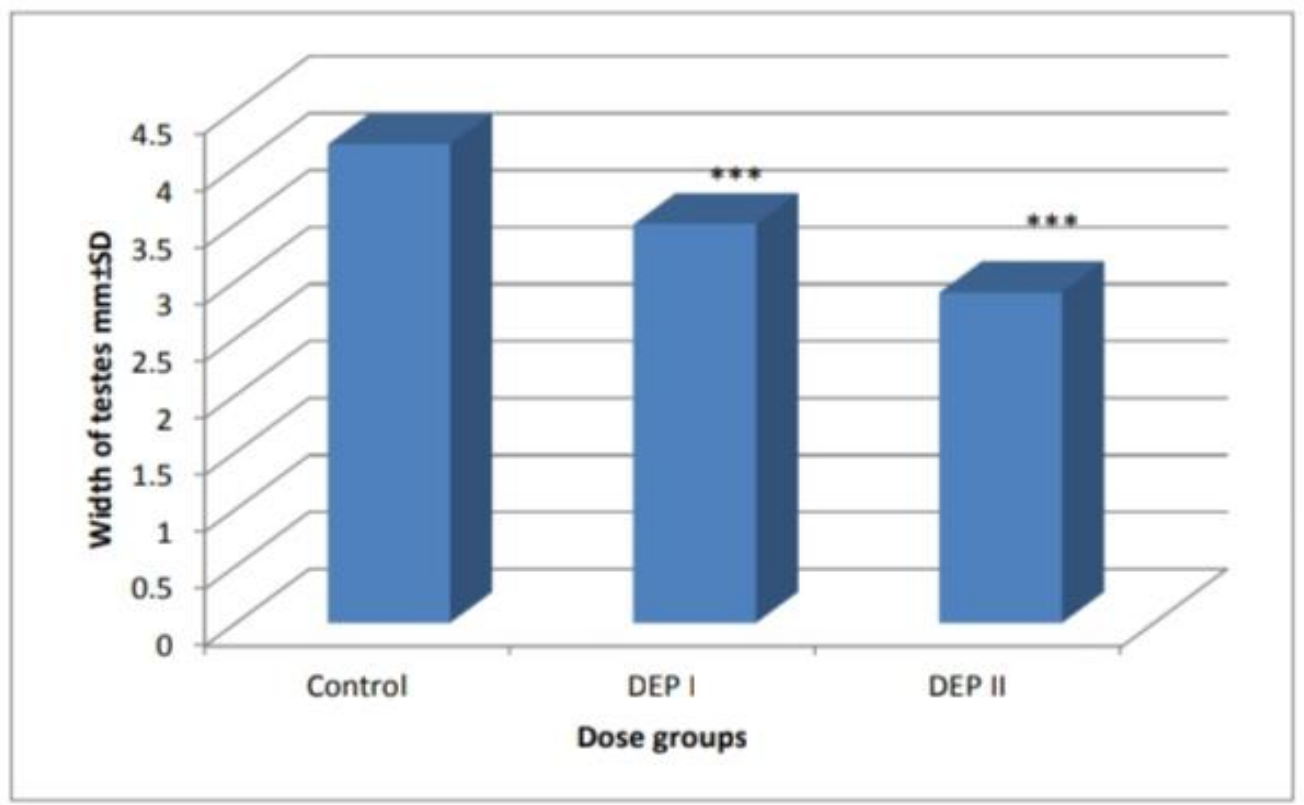

Figure 1.8: Histogram showing the effect of DEP on the width of testes of 8-week-old mouse. The significant difference against $* * *=p<0.001$

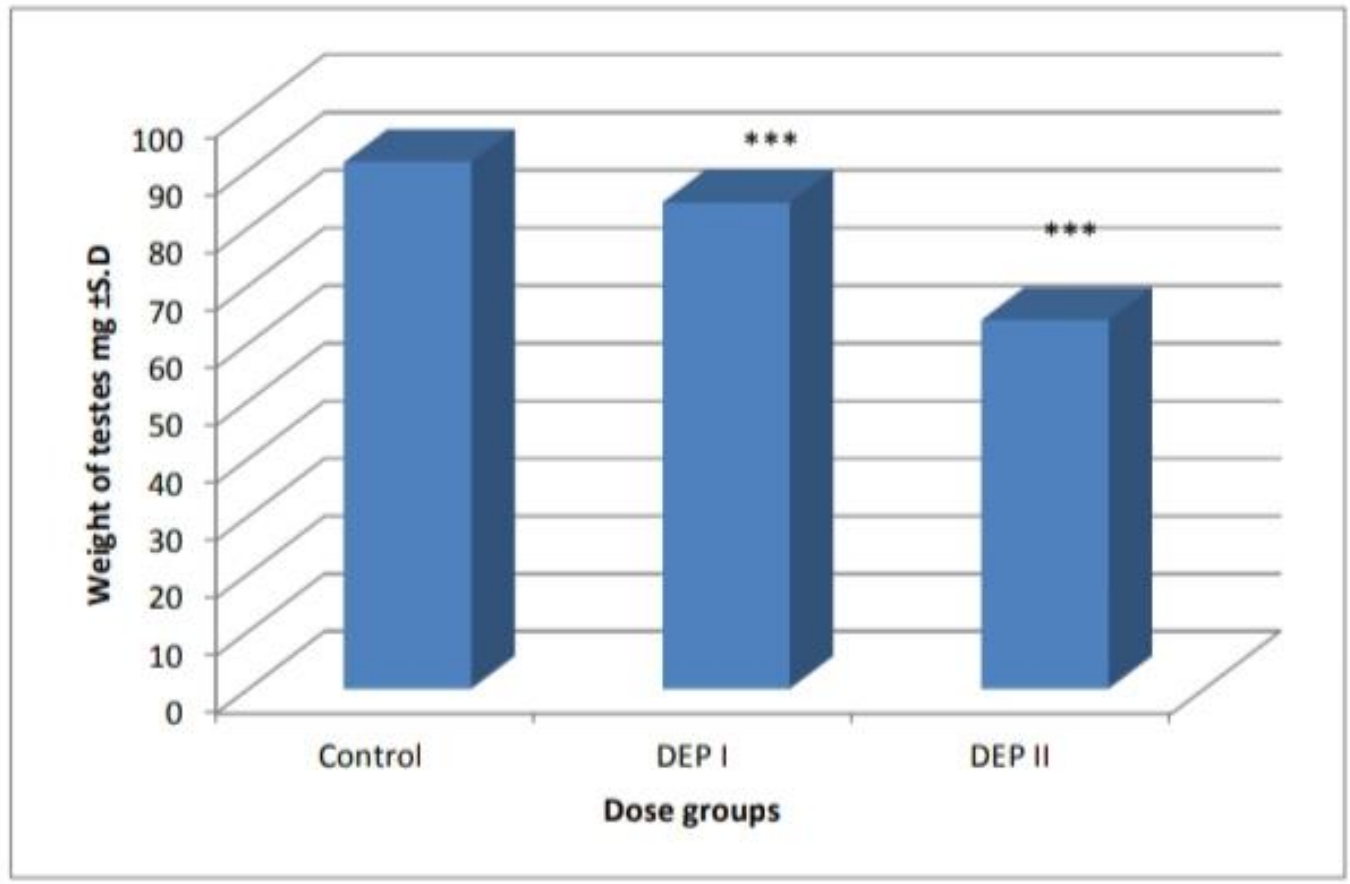

Figure 1.9: Histogram showing the effect of DEP on the weight of testes of 8-week-old mouse.

Note: Asterisks indicate the significant difference against $* * *=p<0.001$ 
International Journal of Engineering Applied Sciences and Technology, 2021

Vol. 6, Issue 5, ISSN No. 2455-2143, Pages 47-60

Published Online September 2021 in IJEAST (http://www.ijeast.com)

Analysis of Hormone:

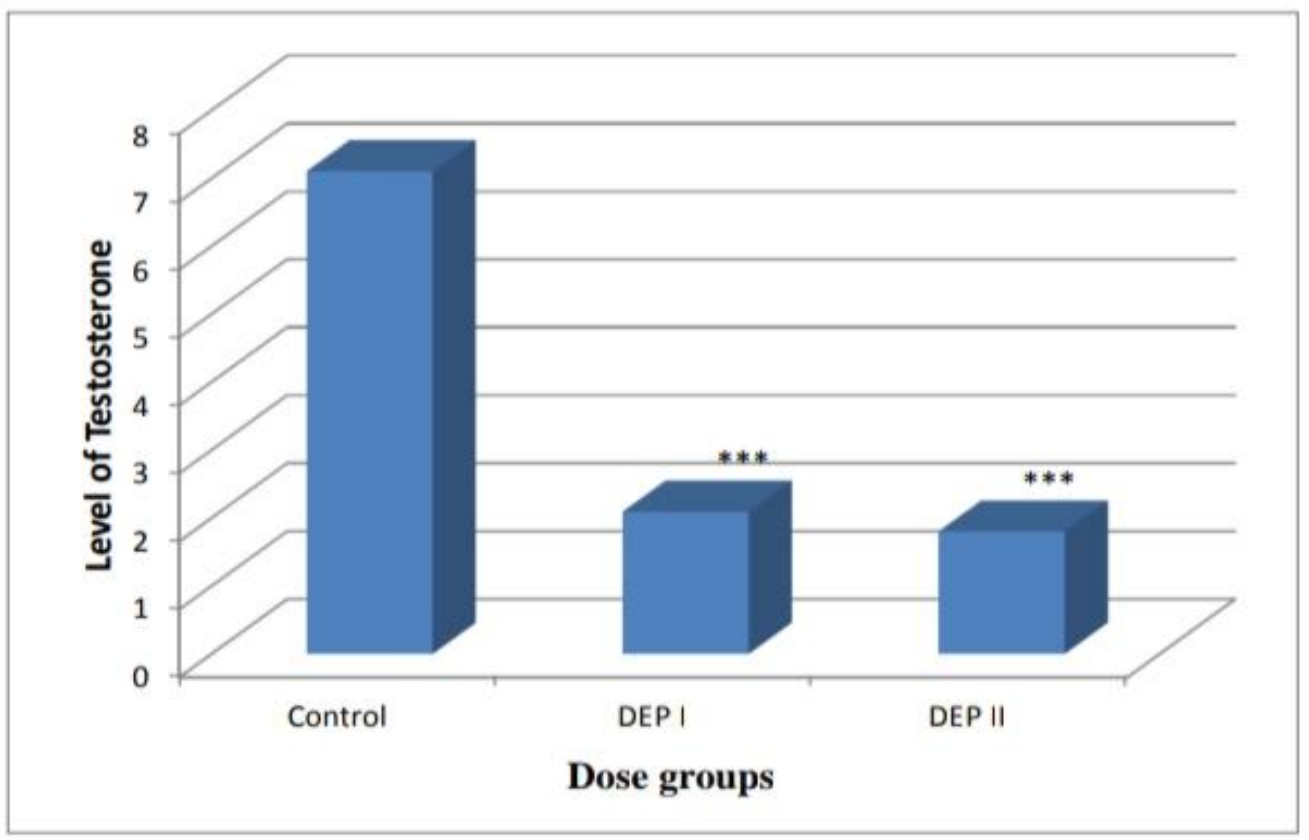

Figure 1.10: Histogram showing the effect DEP on blood testosterone level in 8-week-old mouse.

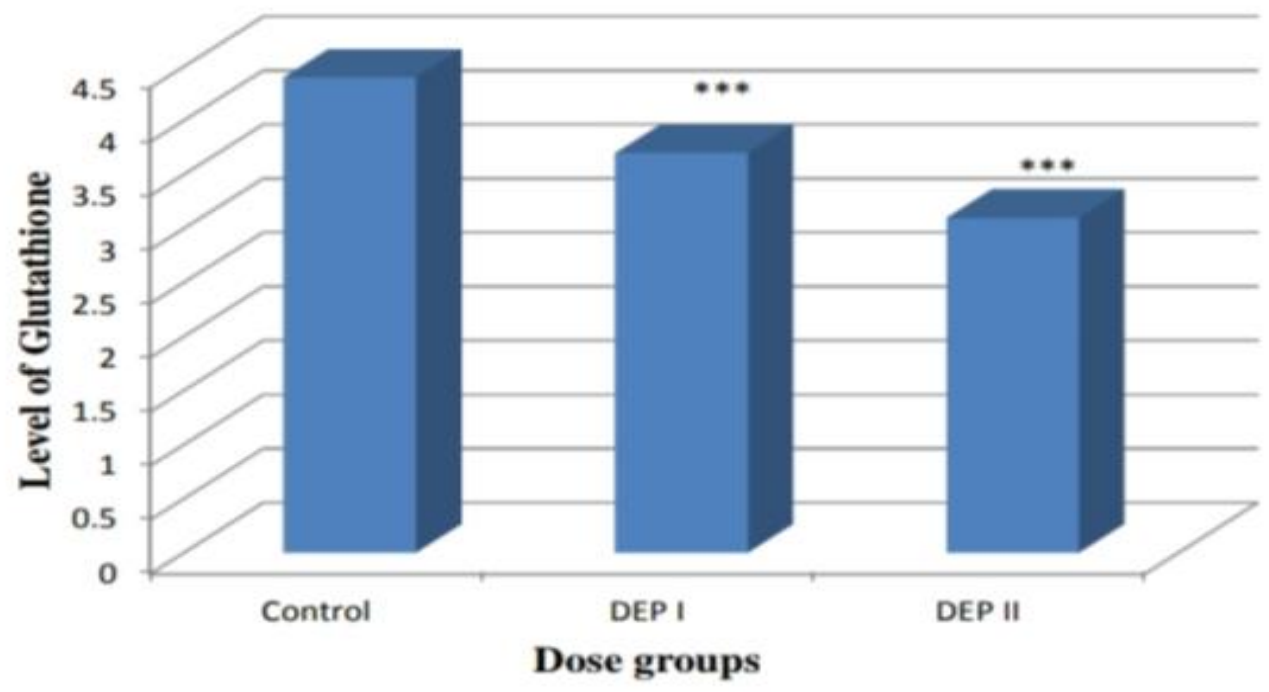

Figure 2.1: Histogram showing the effect DEP on Glutathione level in 8-week-old mouse. 
International Journal of Engineering Applied Sciences and Technology, 2021

Vol. 6, Issue 5, ISSN No. 2455-2143, Pages 47-60

Published Online September 2021 in IJEAST (http://www.ijeast.com)

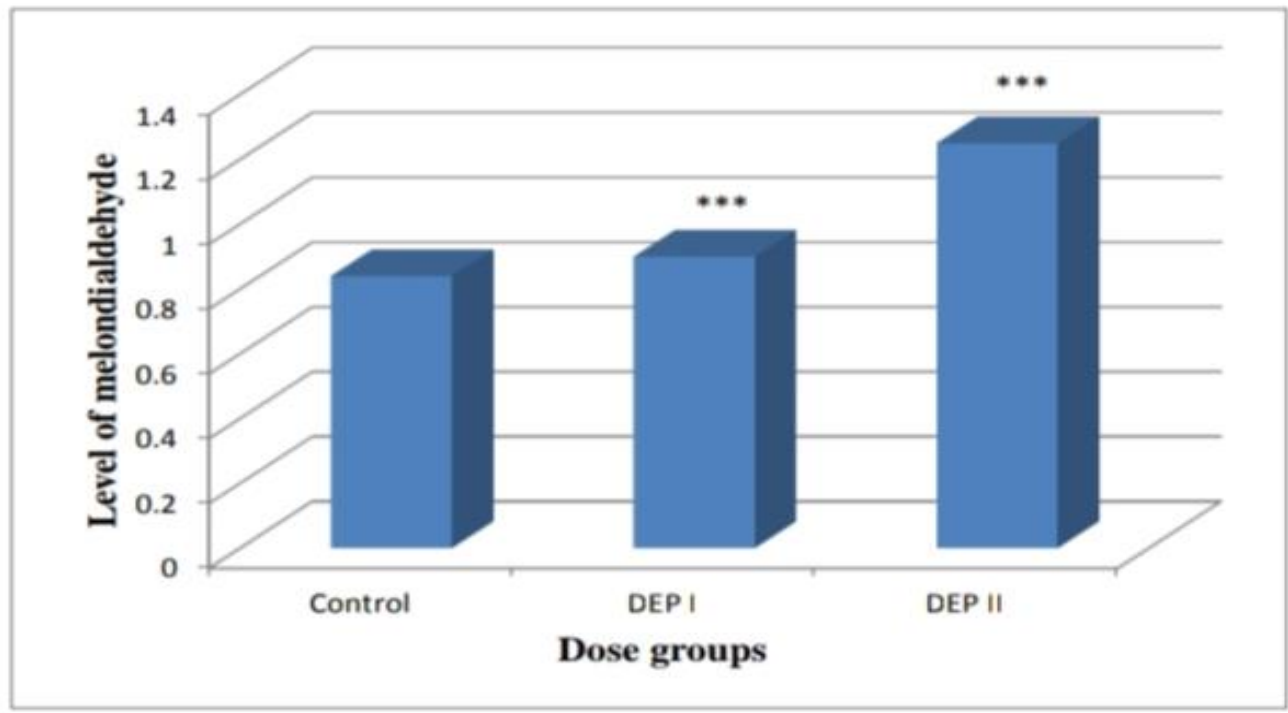

Figure 2.2: Histogram showing the effect of DEP on Malondialdehyde (MDA) level in 8-week-old mouse.

Table 2: Effect of Diethyl Phthalate on blood testosterone, Glutathione and Malondialdehyde (MDA) level in 8-week-old mouse

\begin{tabular}{|l|l|l|l|}
\hline Dose group & $\begin{array}{l}\text { Level of Testosterone } \\
(\mathrm{mg} / \mathrm{ml}) \pm \text { S.D }\end{array}$ & $\begin{array}{l}\text { Level of Glutathione } \\
(\mathrm{mg} / \mathrm{ml}) \pm \text { S.D }\end{array}$ & $\begin{array}{l}\text { Level } \\
\text { Malondialdehyde } \\
(\mathrm{MDA}) \\
(\mu \mathrm{mol} / \mathrm{dl}) \pm \text { S.D }\end{array}$ \\
\hline Control & $7.1 \pm 0.08$ & $4.41 \pm 0.05$ & $0.84 \pm 0.005$ \\
\hline DEP I & $* * *$ & $* * * 3.7 \pm 0.15$ & $* * *$ \\
\hline DEP II & $2.09 \pm 0.04$ & $* * * 15 \pm 0.01$ \\
\hline
\end{tabular}

Histological analysis of liver:

Histological analysis was carried out from both groups. It was completed to recognize the histological evidence of deformities and anomalies produced by diethyle phthalate.

\section{Control Group (C):}




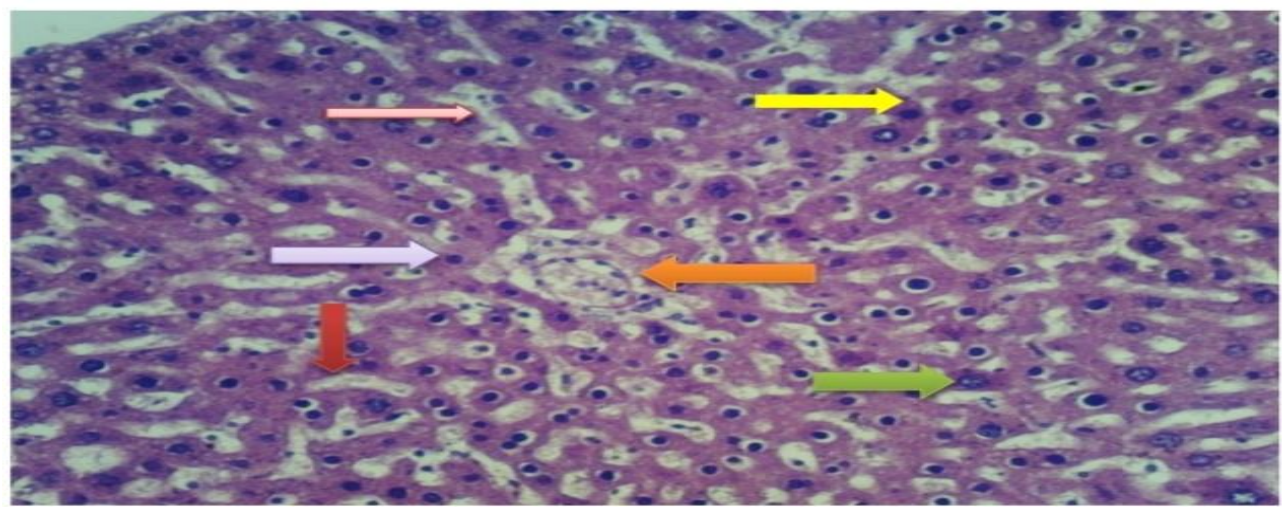

Fig. 2.3: Selected sections (H\&Ex400) of liver of 8-week old mouse of control group control group showing liver histology, Pink arrow: intact and normal association of sinusoids, Yellow arrow: lobular boundary, Green arrow: normal glycogen deposition around the nucleus, Maroon arrow: portal vein, Orange arrow: portal triad, Purple arrow: liver cells

\section{Experimental Group:}

1-Dose group DEP I $(1.2 \mathrm{mg} / \mathrm{g} \mathrm{B.W})$ :

2-Dose group DEP II (1.60 mg/g B.W):

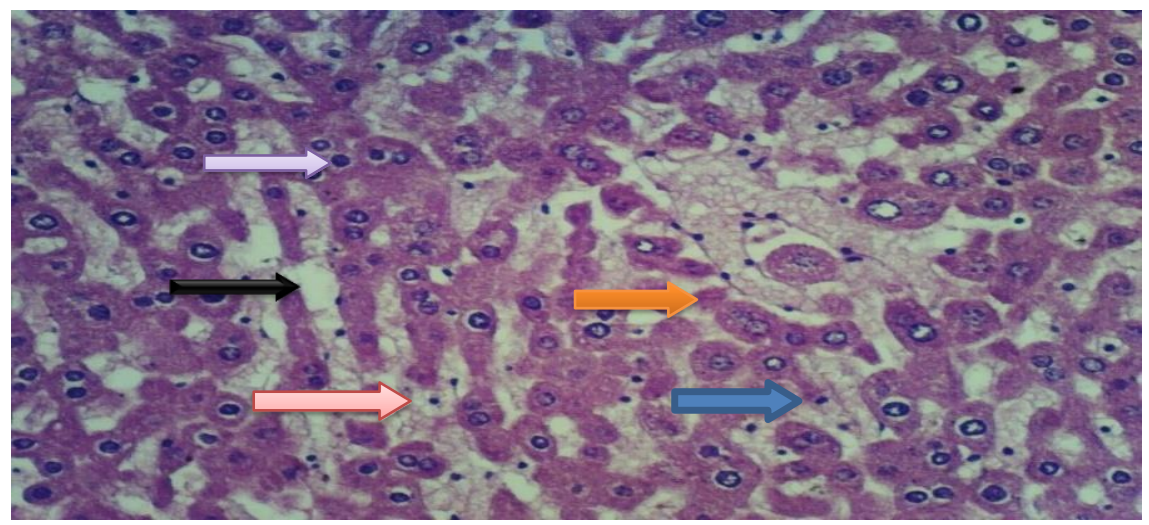

Fig 2.4: Selected sections (H\&Ex400) of liver of 8-week old mouse of experimental group DEP I (1.2 mg/g B.W) showing liver histology, Orange arrow: degenerative cells, Black arrow: vacuolization Blue arrow: Interrupted sheet of hepatocytes, Red arrow: mitotic cell, Purple arrow: mitotic cells.

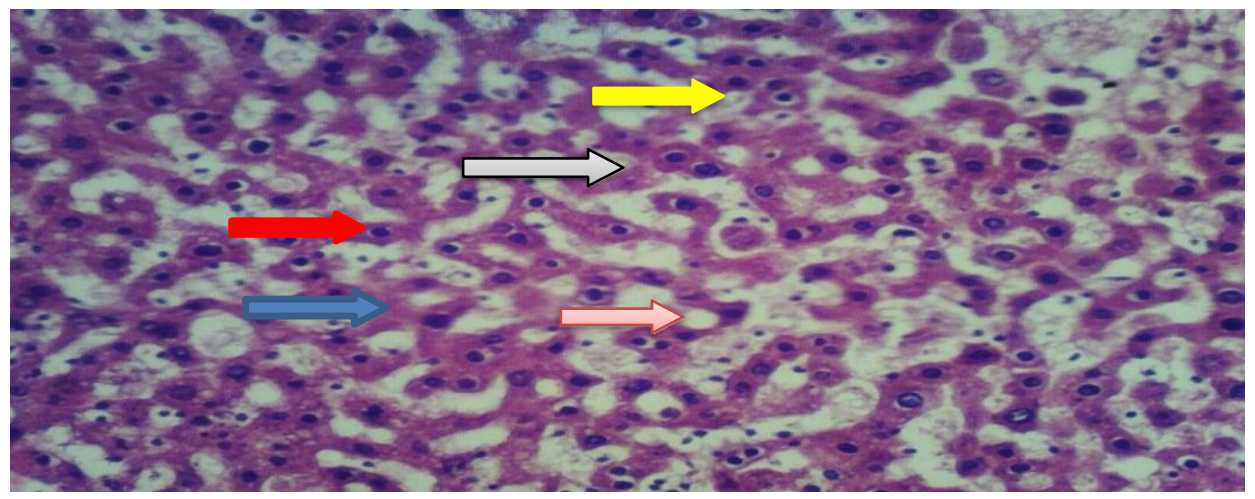




\section{International Journal of Engineering Applied Sciences and Technology, 2021 \\ Vol. 6, Issue 5, ISSN No. 2455-2143, Pages 47-60 \\ Published Online September 2021 in IJEAST (http://www.ijeast.com)}

Fig 2.5: Selected sections (H\&Ex400) of liver of 8-week old mouse of experimental group DEP II (1.60 mg/g B.W) showing liver histology, Grey arrow: absence of bile canaliculus cells, Pink arrow: vacuolization, Red arrow: mitotic cells, Yellow arrow: degenerative cells, Blue arrow: interrupted sheet of hepatocytes

\section{Histological Analysis of Testes}

Analysis of histology was completed on whole groups.

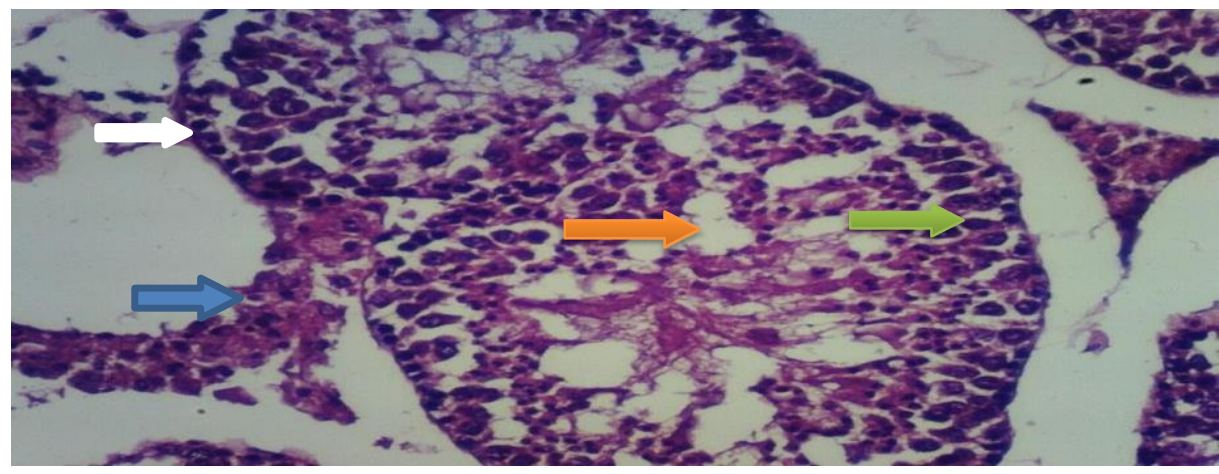

Fig 2.6: Transverse section of testicular tissue of 8-week-old mouse of Control group. Orange arrow: lumen. Green arrow: spermetocytes, Blue arrow: Leydig cells, White arrow: myoid cells.

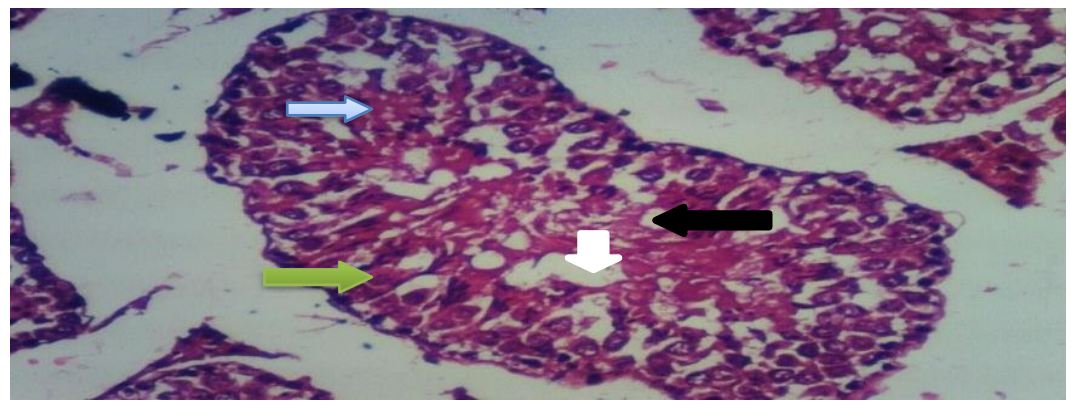

Fig 2.7: Transverse section of testicular tissue 8-week-old mouse of dose group, DEP I(1.2 mg/g B.W), Green arrow: degeneration of spermatids. White arrow: reduced lumen with aspermia Black arrow: vacuolization Light blue arrow: Hyalinization.

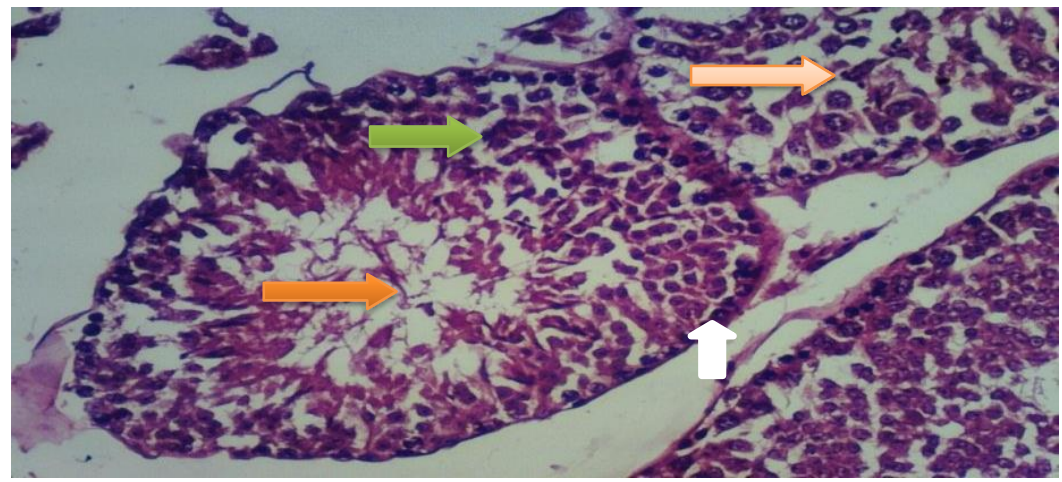

Fig.2.8: Transverse section of testicular tissue of 8-week-old mouse of dose group DEP II (1.60 $\mathbf{~ m g / g ~ B . W ) . ~ W h i t e ~}$ arrow: myoid cell Light Red arrow: elongated spermatids Orange arrow: lumen with reduced sperm cell, Green arrow : spermetocytes. 


\section{International Journal of Engineering Applied Sciences and Technology, 2021 \\ Vol. 6, Issue 5, ISSN No. 2455-2143, Pages 47-60 \\ Published Online September 2021 in IJEAST (http://www.ijeast.com)}

\section{DISCUSSION}

The Diethyle Phthalates (DEP) is generally utilized as plasticizers in the assembling of adaptable PVC items. ${ }^{(5)}$ Huge creation phthalates volume and its broad utilization in clinical, building, and individual consideration items lead to universal human presentation through oral ingestion, inward breath, and dermal contact. ${ }^{(5)(3)}$ In recent study morphological examination was done on both experimental group and control group. In Dose group, DEP I (1.2 mg/g B W) various deformities were observed i.e. wrinkled surface, shrinkage and reduced size of testes. (Fig $1.1,1.2,1.3,1.4)$. While in dose group, DEP II (1.60 $\mathrm{mg} / \mathrm{g} \mathrm{BW}$ ) showed abnormalities in their size, appearance, shape, their surface become wrinkled and shrinkage of cell also observed (Fig 1.5, 1.6).In Morphometric analysis the control and experimental group showed significant results regarding length, width and weight. In control group there is no certain change in the weight, length and width of testes of male mice ( Fig. 1.7, 1.8, 1.9) whereas in dose group, DEP 1 (1.2 mg/g B.W) and DEP II $(1.60 \mathrm{mg} / \mathrm{g} \mathrm{B.W})$ showed the significant effects on decreasing length, width and weight of testes in both groups (Fig 1.10, $2.1,2.2){ }^{(13)}$

The Diethyle Phthalates (DEP) have been appeared to inspire differentiating consequences for liver and testes which cause the generation of testicles and advancing strange liver cell expansion and carcinogenesis. ${ }^{(16)}$ The testicular impacts portrayed reduction in the general seminiferous tubule changes like histological changes and change in weight of organ. In the current examination, we analyze the impacts on testes and liver caused by DEP to all the more likely comprehend the systems cause the degeneration in testicles caused by phthalate. In the current experiment, the glutathione level has decreased after the intake of dose in male mice. Experimental group show decreased level of glutathione while control group show the normal level (Fig: 2.1, Table: 2). Usage of DEP shown essential decline of Glutathione hormone in dosage groups than control group. ${ }^{(\mathbf{1 9})}$ In the recent experiment the level of Malondialdehyde (MDA) significantly increased after administration of certain doses. ${ }^{(15)}$ In control group, MDA level remains normal while in experimental group, MDA level increases and the antioxidant enzyme of testicles, glutathione peroxidase (GPx) and a hormone testosterone significantly decreased.In recent study, liver histological examination has done to show the results of experimental and control group. In control group, normal deposition of glycogen, normal and intact association of sinusoid, portal vein, with complete lobular boundary, and appearance of hepatocytes has been observed (Fig 2.3). In dose group, DEP I (1.2 $\mathrm{mg} / \mathrm{g} \mathrm{B}$.W) showed defects like appearance of mitotic cells, degeneration of hepatocytes, broad sinusoidal spacing and degeneration of kuppfer cells observed (Fig 2.4), while in DEP II (1.60 mg/g B.W) showed abnormalities like interrupted sheet of hepatocytes, vacuolization, degenerative cells and absence of coniculus cells was observed (Fig.2.5 ). In recent histological analysis, control group of testes showed the sperm located in lumen of tubules, round shape seminiferous tubules, germinal epithelium, interstitial cells and peritubular myoid cells in same location (Fig: 2.6) while in experimental group, different deformities observed as vacuolization, interstitial cells rupturing, lumen occupied with destroyed sperm, degenerative sperms, germinal epithelium rupturing, and hyalinization (Fig 2.7, 2.8). Testicular poisonousness of DEP reduction in size, ultimately causing decay of testicular cells, decreased sperm of epididymis. ${ }^{(10)}$ Gonad toxic centralizations of DEP may prompt brought down sperm motility, decay of seminiferous tubules, and actuated basic anomalies in sperm in view spermatids lose the level of zinc. ${ }^{(20)}$ The Sertoli cells of an experimental group decrease the number as compared to control while administrating the Di (n-Butyl). In such manner, it has been stated that the creation of sperm and the size of testes exceptionally corresponded by the Sertoli cells. $^{(8)}$

\section{CONCLUSION}

It is concluded from the research project that Diethyle Phthalate (DEP) is most harmful substance in our environment. DEP toxicity differs in different individuals at various dosages. Histological, morphological and morphometrical observations clearly indicate the toxic impact of DEP on testes and liver of mice. It is additionally noticed that DEP exerts sharp variations in testosterone level content is causing these defects ultimately. Variations are also observed in stress mediators like Glutathione and MDA. It is derivative from the recent analysis that the environmental introduction to DEP can be correspondingly dangerous to not only mice but also for man.

\section{REFERENCES}

1. Noriega NC, Howde shell KL., Furr J., Lambright CR., Wilson VS., Gray LE Jr. (2009). Pubertal administration of DEHP 


\section{International Journal of Engineering Applied Sciences and Technology, 2021 \\ Vol. 6, Issue 5, ISSN No. 2455-2143, Pages 47-60 \\ Published Online September 2021 in IJEAST (http://www.ijeast.com)}

delays puberty, suppresses testosterone production, and inhibits repro-ductive tract development in male Sprague-Dawley and Long-Evans rats. Toxicol Sci, 111:163-178

2. R. M. David, (2006). Proposed Mode of Action for In Utero Effects of Some Phthalate Esters on the Developing Male Reproductive Tract,\| Toxicologic Pathology, vol. 34, no. 3, pp. 209-219.

3. Sharpe, R.M.; Skakkebaek, N.E. (2008). Testicular dysgenesis syndrome: Mechanistic insights and potential new downstream effects. Fertil. Steril, 89, 33-38.

4. T. J. Doyle, J. L., Bowman, V. L., Windell, D. J., McLean, andK. H.,Kim,(2013). Transgenerational effects of Di-(2ethylhexyl) phthalate on testicular germ cell associations and spermatogonial stem cells in mice,\| Biology of Reproduction, 88 (5), 112

5. PatrickR.HannonandJodiA.Flaws,(2015).Th eeffectsofphthalatesontheovary.frontiers in Endocrinology, 6, 8:1.

6. Tran, T.M.; Kannan, K. (2015) Occurrence of phthalate diesters in particulate and vapor phases in indoor air and implications for human exposure in Albany, New York, USA. Arch. Environ. Contam. Toxicol, 68, 489-499.

7. López-Carrillo, L.; Hernández-Ramírez, R.U., Calafat, A.M., Torres-Sánchez, L., Galván-Portillo, M., Needham, L.L., RuizRamos, R., Cebrián, M.E. (2010). Exposure to phthalates and breast cancer risk in Northern Mexico. Environ. Health Perspect, 118, 539-544.

8. Scott HM, Hutchinson GR, Mahood IM, Hallmark N., Welsh M., De Gendt K, (2007).

Role of androgens in fetal testis, development and digenesis. Endocrinology; 148: 2027- 2036.

9. Nandini Bhattacharya, Jannette M. Dufour, My-Nuong Vo., Janice Okita, Richard Okita,and Kwan Hee Kim, (2015). Differential Effects of Phthalates on the Testis and the Liver. Biology of reproduction, 72, 745-75.

10. Ajay Pradhan, Per-Erik, Olsson,Jana Jass (2018).Di (2-ethylhexyl) phthalate and diethyl phthalate disrupt lipid metabolism, Chemosphere, 190, 375-382.

11. Ali S., Steinmetz G., Montillet G., Perrard MH., Loundou A., Durand P., Guichaoua MR; Prat O, (2014). Exposure to low-dose bisphenol A impairs meiosis in the rat seminiferous tubule culture model: a physiotoxicogenomic a pproach. 9, e106245.

12. Akingbemi BT, Youker RT., Sottas CM., Ge R., Katz E., Klinefelter GR., Zirkin BR., Hardy MP. (2001). Modulation of rat Leydig cell steroidogenic function by di (2ethylhexyl) phthalate. Biol Reprod, 65:1252- 1259 .

13. Contzen Pereira, Kranti Mapuskar, C. Vaman Rao. (2008). Effect of diethyl phthalate on rat testicular antioxidant system: Adose-dependent toxicity study. Pesticide Biochemistry and Physiology, 90, (1) $52-57$

14. D. K. Agarwal, S. Eustis, and J. C., Lamb IV, (2012). Effects of diethyle phthalate on the gonadal pathophysiology, sperm morphology, and reproductive performance of male rats, \| Environmental Health Perspectives, 65, 343-350.

15. Erkekoglu P, Zeybek ND., and Giray B. K (2014). The effects of di (2-ethyl) phthalate on rat liver in relation to selenium status, International Journal of Clinical and Experimental Pathology, 95:64-77.

16. Nandini Bhattacharya, Jannette M., Dufour, My-Nuong Vo., Janice Okita., Richard Okita,and Kwan Hee Kim, (2015). Differential Effects of Phthalates on the Testis and the Liver. Biology of reproduction, 72, 745-75.

17. Yingyin Sun, Jing cao Shen, Lin Zeng., Dan Yang, Shuxin Shao, Jinglei Wang, Jie Wei., Junping Xiong, Jiaxiang Chen., (2018). Role of autophagy in di-2-ethylhexyl phthalate (DEHP)-induced apoptosis in mouse Leydig cells, Environmental Pollution, 243,563-572.

18. Y. Jia., T. Liu., L. Zhou (2016). Effects of Di-(2-ethylhexyl) Phthalate on lipid Metabolism by the JAK/STAT Pathway in Rats, || International Journal of Environmental Research and Public Health, 13(11) 1085 .

19. Latini, G. (2005). Monitoring phthalate exposure in humans. Clin. Chim. Acta, 361, $20-29$.

20. Hai Tao GAO, Qian-Nan Di, Liang-Liang Qian, Lingeng Lu., Rui-Xian Li., Wei-Xin Cao., QianXu. (2020). Zinc supplement ameliorates phthalates-induced reproductive toxicity in male rats, Chemosphere, 246, 125828 . 